Eur J Clin Chem Clin Biochem

1995; 33:195-199

(c) 1995 Walter de Gruyter \& Co.

Berlin · New York

\title{
The Endogenous Scavengers in Cerulein-Induced Acute Pancreatitis
}

\author{
By Tijen Tanyalçın ${ }^{1}$, Eser Yıldırım Sözmen ${ }^{1}$, Dilek Taşkaran' ${ }^{1}$ Ömer Özütemiz ${ }^{2}$, Yücel Batur ${ }^{2}$ and Fatma Kutay ${ }^{1}$ \\ 1 Department of Biochemistry \\ 2 Department of Gastroenterology \\ Bornova 35100 Izmir; Turkey
}

(Received September 26, 1994/January 6, 1995)

Summary: Studies in animal models suggest that oxygen radicals are important in the pathogenesis of acute pancreatitis. Cerulein, a decapeptide isolated from the skin of the frog, Hyla caerula, is closely related to the $\mathrm{C}$-terminus of cholecystokinin and it is a potent stimulant of pancreatic exocrine secretion. The aim of the present study was to measure the activity of endogenous scavengers, superoxide dismutase, catalase and glutathione levels in cerulein-induced acute pancreatitis in rats. We found that the plasma amylase and ribonuclease levels in the pancreatitis group were both significantly high $(p<0.01, p<0.05$, respectively) when compared with the control group. Although superoxide dismutase and glutathione levels of pancreatic tissue were decreased significantly $(p<0.01, p<0.01$ respectively), we observed a significant increase $(p<0.01)$ in catalase activity in the cerulein treated group compared to the control group. Therefore, we concluded that the profound alteration of the activities of endogenous scavengers (superoxide dismutase, catalase) and glutathione depletion occuring after cerulein-induced pancreatitis seemed to be important in tissue injury and may provide the basis for successful therapy of the disease.

\section{Introduction}

Acute pancreatitis is caused by autodigestion of pancreatic tissue induced by activated proteolytic enzymes (1). Recent reports suggest that oxygen-derived free radicals play an important role in the pathogenesis of acute pancreatitis $(1-8)$. Under physiological conditions the small amounts of these highly reactive and toxic radicals are detoxified by endogenous free radical scavengers. These biochemical defences include both low molecular mass free radical scavengers such as vitamin $\mathrm{E}$, ascorbate and complex enzyme systems such as superoxide dismutase $\left.^{1}\right)$, catalase ${ }^{1}$ ) and glutathione peroxidase $(2,9)$. Because of the high reactivity, oxygen radicals are difficult to measure directly. One possibility is to measure the amount of lipid peroxidation in the tissue and compare it with the development of tissue injury (5). An-

\footnotetext{
1) Enzymes:

Superoxide dismutase EC 1.15.1.1

Catalase EC 1.11.1.6
}

other indirect way of evaluating the role of the oxygen radicals can be the observation of the alteration in the antioxidant enzyme activity following acute inflammation. Guice et al. (10) showed an in vivo cerulein induced pancreatitis model in which pretreatment with superoxide dismutase and catalase reduced pancreatic damage normally observed.

Cerulein, a decapeptide isolated from the skin of the frog, Hyla caerula, is closely related to the $C$ terminal octapeptide of cholecystokinin and it is a potent stimulant of pancreatic exocrine secretion and, in supramaximal doses of $5 \mu \mathrm{g} / \mathrm{kg}$ per hour, induces acute pancreatitis in rats $(10,11)$. Binding of cerulein on the pancreatic acinar cell triggers a series of cytoplasmic reactions that ultimately cause exocytosis of secretory products, but in very high doses $(5 \mu \mathrm{g} / \mathrm{kg}$ per hour) acts to induce acute cellular injury (12).

In this experiment, to observe the effect of cerulein-induced acute pancreatitis on the biochemical defences, 
we measured the activity of endogenous scavengers, superoxide dismutase, catalase and the level of glutathione.

\section{Materials and Methods}

\section{Reagents and solutions}

All reagents were analytical grade and purchased from Sigma Chem Co (St Louis) and Merck Darmstadt (Germany).

\section{Animals}

Two-months old Swiss-Albino rats, weighing $180-220 \mathrm{~g}$ were used in this experiment. The animals were divided into two groups. The pancreatitis group received cerulein at doses of $20 \mu \mathrm{g} / \mathrm{kg}$ body weight injected in a volume of $5 \mathrm{ml}$ in $9 \mathrm{~g} / \mathrm{l} \mathrm{NaCl}$ intraperitoneally 4 times at one hour intervals. An equal volume of saline alone was administered in the same manner to the control group. The animals were killed by decapitation 12 hours later.

\section{Assays in tissue}

For the assays of superoxide dismutase and catalase, pancreatic tissue specimens were homogenised in phosphate buffer solution $(\mathrm{pH}=7.4)$ in a ratio of $1 / 10$ (weight/volume). After centrifugation at $600 \mathrm{~g}$ for 10 minutes, clear supernatant was used for the measurement of superoxide dismutase and catalase activity.

Measurement of total superoxide dismutase activity was performed according to Misra \& Fridovich based on the inhibition of autoxidation of epinephrine (13). Catalase activity was determined according to the modified method of $\operatorname{Aebi}(14,15)$. The catalase mediated decomposition of $\mathrm{H}_{2} \mathrm{O}_{2}$ was monitored directly at $240 \mathrm{~nm}$.

Total sulphydryl groups and non-protein sulphydryl groups (GSH) were measured according to Sedlak \& Lindsay based on the reaction of Ellman's reagent (5,5'-dithiobis-2 nitrobenzoic acid) (16). After homogenisation of the $200 \mathrm{mg}$ pancreas tissue in $8.0 \mathrm{ml}$ of $0.02 \mathrm{~mol} / 1$ EDTA, aliquots of $0.5 \mathrm{ml}$ and $5.0 \mathrm{ml}$ of the homogenates were used for total sulphydryl groups and GSH, respectively. Protein levels of pancreas tissue were determined according to Lowry et al. (17).

\section{Assays in plasma}

Heparinized blood samples were obtained for the assay of plasma amylase and ribonuclease. Plasma amylase measurement was based on the hydrolysis of starch. The ribonuclease assay was performed by the method of Heppel based on the hydrolysis of polycytidylic acid (18).

Microscopic examination of each group was also performed. For light microscopy, the pancreas tissue of each animal was fixed in buffered formalin and paraffin embedded sections were stained with hematoxylin and eosin.

\section{Statistical analysis}

The results reported in this study represent the mean \pm SEM. Differences between the groups were evaluated using Student's t-test. A p-value $<0.05$ was considered to be statistically significant.

\section{Results}

The alteration in the levels of superoxide dismutase, catalase, GSH and total sulphydryl groups after intraperitoneal cerulein injection are summarized in table 1.

The catalase activity increased significantly $(p<0.05)$ from the control level of $1.62 \pm 0.12$ to $2.91 \pm 0.25$ $\mathrm{U} / \mathrm{mg}$ protein. In contrast, superoxide dismutase activity of the cerulein treated group $(0.88 \pm 0.11 \mathrm{U} / \mathrm{mg}$ protein) decreased significantly $(p<0.01)$ when compared with the control group $(1.59 \pm 0.10 \mathrm{U} / \mathrm{mg}$ protein). Both GSH and total sulphydryl groups levels of cerulein treated group were significantly lower than those of the control group $(p<0.05, p<0.01)$, respectively.

Plasma amylase and ribonuclease levels showed a significant increase $(p<0.01, p<0.05)$ in the pancreatitis group (tab. 2). We found a significant positive correlation between serum amylase and ribonuclease levels in the control group $(r=0.897, p<0.01)$.

After 12 hours following the last cerulein injection, light microscopic examination of the rat pancreatic glands showed no evidence of damage.

Tab. 1 Alteration in the antioxidant defence system in pancreatic tissue after intraperitoneal cerulein injection

\begin{tabular}{lll}
\hline & $\begin{array}{l}\text { Control } \\
\text { group } \\
(\mathrm{n}=10)\end{array}$ & $\begin{array}{l}\text { Cerulein } \\
\text { treated group } \\
(\mathrm{n}=10)\end{array}$ \\
\hline $\begin{array}{l}\text { Superoxide dismutase } \\
\text { (U/mg protein) }\end{array}$ & $1.59 \pm 0.10$ & $\left.0.88 \pm 0.11^{\mathrm{a}}\right)$ \\
$\begin{array}{l}\text { Catalase } \\
\text { (U/mg protein) }\end{array}$ & $1.62 \pm 0.12$ & $\left.2.91 \pm 0.25^{\mathrm{b}}\right)$ \\
$\begin{array}{l}\text { Glutathione } \\
\text { (nmol/mg protein) }\end{array}$ & $6.64 \pm 0.76$ & $\left.4.58 \pm 0.57^{\mathrm{c}}\right)$ \\
$\begin{array}{l}\text { Total sulphydryl } \\
\text { (nmol/mg protein) }\end{array}$ & $64.93 \pm 7.39$ & $\left.31.09 \pm 3.23^{\mathrm{d}}\right)$ \\
\hline
\end{tabular}

Data were given as mean $\pm \mathrm{SEM}$

a), ${ }^{\text {d) }} \mathrm{p}<0.01$

$\left.{ }^{b}\right)$, $) \mathrm{p}<0.05$

Tab. 2 Plasma amylase and ribonuclease levels following cerulein injection

\begin{tabular}{lll}
\hline & $\begin{array}{l}\text { Control } \\
\text { group } \\
(\mathrm{n}=10)\end{array}$ & $\begin{array}{l}\text { Cerulein } \\
\text { treated group } \\
(\mathrm{n}=10)\end{array}$ \\
\hline Amylase kU/1 & $415.71 \pm 23.69$ & $\left.566.66 \pm 4.67^{\mathrm{a}}\right)$ \\
Ribonuclease kU/1 & $18.03 \pm 1.98$ & $\left.23.15 \pm 1.89^{\mathrm{b}}\right)$ \\
\hline
\end{tabular}

Data were given as mean $\pm \mathrm{SEM}$

a) $\mathrm{p}<0.01,{ }^{\mathrm{b}}$ ) $\mathrm{p}<0.05$ 


\section{Discussion}

The common consequence of an injury to the pancreas is the development of an interstitial edema containing proteases, the activation of which governs the progression and severity of the resulting acute pancreatitis (19). Studies in animal models suggest that oxygen radicals may be important in the pathogenesis of acute pancreatitis $(1,2,4-7,20-23)$. In this study we found that the plasma amylase and ribonuclease levels of the cerulein treated group were both significantly higher ( $p<0.01, p<0.05$, respectively) than those of the control group indicating that acute pancreatitis was produced. Kinami et al. showed an increase in serum ribonuclease level for 48 hours after the development of pancreatitis in rat models (24). Furukawa et al. also observed pancreatic edema and elevation of serum amylase activity after the first injection of cerulein (25). However, such biochemical evidence of our experiment could not be supported by histopathological change of pancreatic tissue under light microscopy. Schoenberg et al. (5) reported that the first lesions of pancreatic tissue became apparent after 3-5 hours, affected the entire gland and got worse after 12 hours of continuous cerulein infusion. The early changes were seen by electron microscopy after 30 minutes of cerulein infusion. They also observed that tissue levels of peroxidation products increased, reaching their highest concentrations after 1 hour of cerulein infusion and returning to control values after 3 hours (23). In our experiment, we injected cerulein intraperitoneally at a dose of $20 \mu \mathrm{g} / \mathrm{kg}$ for 4 times at 1 hour intervals. Schoenberg et al. $(5,23)$ treated the rats with a standard dose of cerulein $5 \mu \mathrm{g} / \mathrm{kg}$ per hour by infusion at a rate of $0.6 \mathrm{ml} /$ hour. The differences in experimental models of established studies on cerulein induced acute pancreatitis can be an explanation for obtaining distinct observations. Dabrowski et al. (26) assessed the involvement of oxygen radicals by measuring the levels of reduced glutathione (GSH) and oxidized glutathione (GSSG) and Neuschwander-Tetri et al. also (22) investigated the status of pancreatic glutathione during the development of acute pancreatitis.

The authors found that pancreatic glutathione content decreased remarkably at the early stage of acute pancreatitis and began to rise after cerulein discontinuation. In our experiment, tissue GSH and total sulphydryl group levels significantly decreased. This is consistent with the results of Schoenberg et al. and Neuschwander-Tetri et al. $(22,23)$ and probably indicates that GSH is used in the destructive pathway of reactive oxygen species $(1$, 11 ), and it is an essential component of intracellular defence against oxygen radical-mediated injury. Neuschwander-Tetri et al. (22) examined if the GSH depletion played a critical role in allowing tissue injury to progress by pretreating the animals with glutathione prodrug (glutathione monoethylester) and they concluded that glutathione prodrug prevented the depletion and significantly reduced the biochemical and histological evidence of cerulein induced pancreatitis (22). Dabrowski et al. (26) assumed that the marked decrease in pancreatic non-protein (GSH) and protein sulphydryl groups results from excessive production of oxygen radicals overwhelming the capacity of the endogenous antioxidant mechanism. It has also been shown that glutathione peroxidase activity at 12 hours of the cerulein injection was significantly elevated compared to the basal level at 0 hour (1) and glutathione peroxidase is thought to be increased by the accumulation of lipid peroxides from the chain reaction of oxygen radicals. Similarly, Schoenberg et al. observed a significant reduction of GSH in cerulein induced acute pancreatitis (23). They also regard the decrease of GSH as a manifestation of cellular oxidant stress. Niederau et al. reported that low dose of cerulein shown not to induce pancreatic injury caused moderate GSH depletion and suggested that cerulein induced a loss of GSH by a direct effect rather than a consequence of injury. Rapid consumption or catabolism of glutathione can be alternative explanations for the cerulein-induced pancreatic glutathione depletion $(22,27)$, because irreversible consumption of glutathione can occur in an environment of ongoing lipid peroxidation (28).

Reports of some investigators indicate that species such as superoxide and hydrogen peroxide might be key elements leading to progressive tissue injury in acute experimental pancreatitis $(1,23)$. These highly reactive species are able to attack most biological substrates and cause cell injury through lipid peroxidation. In our study we observed that the endogenous scavengers superoxide dismutase and catalase, which specifically dismutate superoxide and hydrogen peroxide, were affected by the cerulein treatment. While there was a significant $(p<0.01)$ decrease in superoxide dismutase activity, we found a significant increase $(P<0.01)$ in catalase activity. The primary enzymes of the defence system are known as superoxide dismutase, catalase and GSH peroxidase. The second line of defence against oxidant induced cellular injury are non-enzymatic scavengers such as thiols, especially GSH, $\alpha$-tocopherol, carotenoids, ascorbic acid, uric acid and methionine. Free radical scavenging processes in a cell can be both cooperative and antagonistic. The reactions can be cooperative in the sense that catalase and glutathione peroxidase combine to metabolize $\mathrm{H}_{2} \mathrm{O}_{2}$, with catalase contributing more to $\mathrm{H}_{2} \mathrm{O}_{2}$ metabolism at higher $\mathrm{H}_{2} \mathrm{O}_{2}$ concentrations. It has been established that superoxide dismutase can be inhibited by $\mathrm{H}_{2} \mathrm{O}_{2}$ and in the first step this molecule is removed from the cell by NADPH-GSH system $(9,25$, 
26). This explains the marked superoxide dismutase activity and glutatione depletion obtained in our experiment. Then, at higher concentrations of $\mathrm{H}_{2} \mathrm{O}_{2}$, it is reasonable to observe the increased activity of catalase. Probably, dose and time dependent nature of the cerulein treatment affects all these enzyme activities which participate in the antioxidant mechanism. Compensatory increase of catalase against oxygen-derived free radicals may be the result of cerulein treatment causing free radical generation. The difference that we have found between superoxide dismutase and catalase activity might be due to the different substrates and reaction pathways of the 2 enzymes. Nonaka et al. (1) observed decreased activities in both superoxide dismutase and catalase in cerulein induced acute pancreatitis. They suggested that whatever the mechanism of decreased superoxide dismutase and catalase activity, the decreased level of each enzyme might be relevant to the pathological state of pancreatitis. Guice et al. showed in an in vivo cerulein-induced pancreatitis model that pretreatment with superoxide dismutase and catalase reduced pancreatic damage normally ob- served (10). In their study a single past injury injection of superoxide dismutase and catalase was as effective as continuous infusion of these scavengers, given at the same time with cerulein. The pancreas was examined 12 hours after the end of cerulein infusion, at a time when the pancreas is beginning to recover from the cerulein. Schoenberg et al. (5) treated the rats with higher doses of superoxide dismutase and catalase and observed that treatment with superoxide dismutase and catalase either before and after cerulein infusions prevented lipid peroxidation. They concluded that scavenger treatment reduced the tissue damage.

In our experiment, we did not determine the peroxidation products. However, the decrease in GSH and total sulphydryl levels can be regarded as a manifestation of cellular oxidant stress (23). Although the role of oxygen radicals in acute pancreatitis is still obscure, it is clearly known that endogeneous scavengers involved in the antioxidant mechanism are affected in cases of acute pancreatitis and this finding will provide an insight into the advance of disease therapy.

\section{References}

1. Nonaka A, Manabe T, Kyogoku T, Tamura K, Tobe, T. Changes in lipid peroxide and oxygen radical scavengers in cerulein-induced acute pancreatitis. Digestion 1990; 47:130-7.

2. Saluja A, Powers RE, Saluja M, Rudledge P, Steer ML. The role of oxygen-derived free radicals in cerulein-induced pancreatitis. Gastroenterology 1986; 90:1613.

3. Matcovics B, Memeth MCS, Karacsonyi S, Farkas G, Maurer M, Varga SZI, Cavacs A. Correlations between the serum pancreatic enzyme activities and lipid peroxidation in acute pancreatitis. Clinica Chimica Acta 1992; 211:125-7.

4. Braganza J, Rinderknecht $H$. Free radicals and acute pancreatitis. Gastroenterology 1988; 94:1111-2.

5. Schoenberg MH, Buchler M, Gaspar M, Stinner A, Younes M, Melzner I, Bültman B, Beger HG. Oxygen free radicals in acute pancreatitis of the rat. Gut 1990; 31:1138-43.

6. Sanfey H, Bulkley GB, Cameron JL. The pathogenesis of acute pancreatitis. Ann Surg 1985; 201:633-9.

7. Nonaka A, Manabe T, Tamura K, Asano N, Imanishi K, Tobe $\mathrm{T}$. Changes of xanthine oxidase, lipid peroxide and superoxide dismutase in mouse acute pancreatitis. Digestion 1998; 43:41-6.

8. Parks DA, Bulkley GB, Granger DN. Role of oxygen derived free radicals in digestive tract diseases. Surgery 1983; 94/ 3:415-22.

9. Freeman BA, Crapo JD. Biology of disease. Free radicals and tissue injury. Lab Invest 1982; 47/5:412-25.

10. Guice KS, Miller DE, Oldham KT, Townsend CM, Thompson JC. Superoxide dismutase and catalase; a possible role in established pancreatitis. Am J Surg 1986; 151:163-9.

11. Bieger W, Marin-Achar A, Bassler M, Kem HF. Studies on intracellular transport of secretory proteins in the rat exocrine pancreas. IV. Stimulation by in vivo infusion of caerulein. Cell Tissue Res 1976; 165:435-53.

12. Lampel $M, K e r n$ HF. Acute interstitial pancreatitis in the rat induced by excessive doses of a pancreatic secretagogue. Virchows Arch A 1977; 373:97-117.

13. Misra HP, Fridowich I. The role of superoxide anion in the autooxidation of epinephrine and a simple assay for superoxide dismutase. J Biol Chem 1972; 247:3170-5.

14. Aebi H. Catalase in vitro. Methods in Enymol 1984; 105:121-6.

15. Sözmen EY, Tanyalçın T, Onat T, KutayF, Erlaçin S. Ethanol induced oxidative stress and membrane injury in rat erythrocytes. Eur J Clin Chem Clin Biochem 1994; 32:741-4.

16. Sedlak J, Lindsay RH. Estimation of total, protein-bound, and nonprotein sulfhydryl groups in tissue with Ellman's reagent. Anal Biochem 1968; 25:192-205.

17. Lowry OH, Rosebrough NJ, Fart AL, Randall RJ. Protein measurement with the folin phenol reagent. J Biol Chem 1951; 193:265-75.

18. Jung $K$. An optimized micromethod for determining the catalytic activity of serum ribonuclease. J Clin Chem Clin Biochem 1986; 24:243-50.

19. Adler G, Rohr G, Kern HF. Alteration of membrane fusion as a cause of acute pancreatitis in the rat. Dig Dis Sci 1982; 27:993-1002.

20. Wisner J, Green D, Ferrel L, Renner I. Evidence for a role of oxygen derived free radicals in the pathogenesis of caerulein induced acute pancreatitis in rats. Gut 1988; 29:1516-23.

21. Sanfey H, Sarr MG, GB Bulkey, Cameron JL. Oxygen-derived free radicals and acute pancreatitis: a review. Acta Physol Scand Suppl 1986; 548:109-18.

22. Neuschwander-Tetri BA, Ferrell LD, Sukhabotr RJ, Grendell, $\mathrm{JH}$. Glutathione monoethyl ester ameliorates caerulein induced pancreatitis in the mouse. J Clin Invest 1992; 89:109-16.

23. Schoenberg $M H$, Büchler M, Berger HG. Oxygen radicals in experimental acute pancreatitis. Hepato-Gastroenterol 1994; 44:313-9.

24. Kinami Y, Kita I. Relationship between pancreatic enzymes and pathological changes in the pançreas in acute pancreatitis. 
The significance of determination of serum deoxyribonuclease. Int J Pancreatol 1989; 4:371-81.

25. Furukawa $M$, $T$ Kimura, Yamaguchi $H$, Kinjoh $M$, Nawata $H$. Role of oxygen-derived free radicals in hemorrhagic pancreatitis induced by stress and cerulein in rats. Pancreas 1994; 9:67-72.

26. Dabrowski A, Chwiecko M. Oxygen radicals mediate depletion of pancreatic sulfhydryl compounds in rats with ceruleininduced acute pancreatitis. Digestion 1990; 47:15-8.

27. Niederau C, Liddle RA, Ferrell LD, Grendell JH. Beneficial effects of cholecystokinin-receptor blockade and inhibition of proteolytic enzyme activity in experimental acute hemorrhagic pancreatitis in mice. J Clin Invest 1986; 78:1056-63.
28. Poot M, Verkerk A, Koster JF, Esterbauer H, Jongkind JF. Influence of cumene hydroperoxide and 4-hydroxynonenal on the glutatione metabolism during in vitro ageing of human skin fibroblasts. Eur J Biochem 1987; 162:287-91.

Tijen Tanyalçın, MD., PhD.

Ege University School of Medicine

Department of Biochemistry

Bornova 35100 Izmir

Turkey 
